\title{
Baseline NIH Stroke Scale Responses Estimate the Probability of Each Particular Stroke Subtype
}

\author{
E.C. Leira ${ }^{a}$ H.P. Adams Jr. ${ }^{a} \quad$ G.E. Rosenthal ${ }^{b} \quad$ J.C. Torner ${ }^{c}$ \\ Departments of a Neurology and ${ }^{\mathrm{b}}$ Internal Medicine, Carver College of Medicine, and \\ 'Department of Epidemiology, College of Public Health, University of lowa, lowa City, lowa, USA
}

\section{Key Words}

Acute stroke diagnosis $\cdot$ Stroke scales $\cdot$ Clinical

symptomatology, syndromes $\cdot$ Clinical diagnosis, patterns .

Stroke subtype $\cdot$ Mechanisms of stroke $\cdot \mathrm{NIH}$ stroke scale

\begin{abstract}
Background: Emergency treatment of ischemic stroke should ideally be mechanism specific, but acute subtype diagnosis is problematic. Since different subtypes often are associated with specific patterns of neurological deficits, we hypothesize that scores on baseline NIH stroke scale (NIHSS) items may help emergently stratify patients by their probability of having a particular stroke subtype. Methods: We performed multivariate polytomous logistic regression analyses on 1,281 patients enrolled in the Trial of ORG 10172 in Acute Stroke Treatment (TOAST). We tested the predictive value of individual items to the baseline NIHSS exam, and syndromic combinations of those items, in anticipating the TOAST stroke subtype at 3 months adjusting for atrial fibrillation. We then used the most significant NIHSS items to construct a predictive model. Results: The NIHSS items that discriminate between stroke subtypes are language, neglect, visual field and brachial predominance of weakness. Among patients without atrial fibrillation, a normal score for these 4 variables conveys a $46 \%$ chance of lacunar stroke, $12 \%$ of atherothrombotic stroke and $10 \%$ of cardioembolism. This
\end{abstract}

pattern gradually reverses with increased numbers of abnormal responses. Those with abnormalities in all 4 items have a $0.1 \%$ chance of lacunar stroke, $50 \%$ of atherothrombotic stroke and $39 \%$ of cardioembolism. Conclusions: Language, neglect, visual fields and brachial predominance of weakness in the baseline NIHSS help discriminate between subtypes, particularly between lacunar and nonlacunar strokes. Clinical trials testing interventions aimed to particular stroke mechanisms may use these NIHSS items to emergently stratify patients based on their probability of having a particular stroke subtype.

Copyright $\odot 2008$ S. Karger AG, Basel

\section{Background}

There is an interest in focusing acute interventions on the stroke subtypes that are most likely to benefit $[1,2]$. Such an approach would require a reliable clinical diagnosis of stroke subtype in the emergency department. Unfortunately, acute subtype diagnosis remains problematic because the clinical estimate alone is often inaccurate [3]. The required diagnostic ancillary tests [4] may be time-consuming or not available on an emergent basis [5]. As a result, acute stroke trials are struggling to reliably stratify patients by subtype using clinical means [6]. Therefore, a system that applies scores from early clinical

\section{KARGER}

(c) 2008 S. Karger AG, Basel

Fax +41613061234

E-Mail karger@karger.ch

www.karger.com
Accessible online at:

www.karger.com/ced
Enrique C. Leira, MD, MS

Department of Neurology, 2147-RCP, University of Iowa Hospital

200 Hawkins Drive

Iowa City, IA 52242 (USA)

Tel. +1 319356 8755, Fax +1 319384 7199, E-Mail enrique-leira@uiowa.edu 
Table 1. Significant NIHSS variables that differentiate between stroke subtypes in 2 polytomous logistic regression models adjusted for atrial fibrillation

\begin{tabular}{lcllc}
\hline $\begin{array}{l}\text { Including only patients with a defined stroke subtype } \\
\text { (lacunar, atherothrombotic, cardioembolic) }(\mathrm{n}=812)\end{array}$ & & \multicolumn{2}{l}{$\begin{array}{l}\text { Including all patients in the TOAST database (lacunar, athero- } \\
\text { thrombotic, cardioembolic, 'other' and 'undetermined') }(\mathrm{n}=1,281)\end{array}$} \\
\cline { 1 - 1 } NIHSS variable & $\mathrm{p}$ value & & NIHSS variable & p value \\
\hline Best language & $<0.0001$ & & Best language & $<0.0001$ \\
Brachial predominance of weakness & 0.01 & & Brachial predominance of weakness & 0.04 \\
Visual fields & 0.02 & & Visual fields & 0.02 \\
Neglect & NS & & Neglect & 0.02 \\
\hline
\end{tabular}

The first model was performed only in patients with a defined stroke subtype (lacunar, atherothrombotic and cardioembolic). The second model was performed in the whole TOAST population (including 'other' and 'undetermined' strokes).

scales to select patients based on their probability of having certain stroke subtypes [7] might permit selection of subtype-specific acute interventions, particularly since time is of the essence, and acute neuroimaging resources are limited.

The NIH Stroke Scale (NIHSS), an instrument for the neurological assessment of patients [8], is widely used in the initial evaluation of patients with ischemic stroke by a wide variety of professionals. It is already known that the patterns of brain lesions [9], and corresponding neurological impairments [10], differ between stroke mechanisms. Therefore, it is expected that certain items of the NIHSS may be associated with particular stroke subtypes of the Trial of ORG 10172 in Acute Stroke Treatment (TOAST). The aims of this study were (1) to determine which NIHSS items independently discriminate between stroke mechanisms and the strength of such association, and (2) to generate a model probability for each particular stroke subtype based on abnormal scores in those NIHSS items.

\section{Methods}

Data collected from 1,281 patients enrolled in the doubleblinded placebo-controlled TOAST were examined. The design of this trial has been reported elsewhere [11]. The data included scoring of the baseline NIHSS of each patient performed by a local investigator that had previously completed a certification process [8]. A TOAST stroke subtype determination at 3 months was performed by the principal investigator (H.P.A.) using standardized criteria after reviewing the available records and tests [4]. Since the treatment allocation (danaparoid vs. placebo) would not influence pretreatment baseline NIHSS or stroke subtype determination, data from both treatment arms of the trial were combined as a prospective cohort.
Twenty potential NIHSS predictors were analyzed. We considered 13 items of the NIHSS as dichotomous variables $(0=$ 'normal', $>0$ = 'abnormal'). Right and left arm scores were combined as 'arm motor', and right and left leg scores as 'leg motor'. Items graded as 9 ('untestable') were considered as 'missing' responses for analysis. We also created 7 different combinations of NIHSS responses that replicate clinical syndromes used in clinical practice that could be suggestive of certain stroke subtypes. These syndromes included 'pure motor syndrome' (abnormal motor arm and motor leg, with or without dysarthria or facial weakness, with normal remaining NIHSS items), 'pure sensory syndrome' (abnormal sensory with normal remaining NIHSS items), 'aphasia-hemiparesis' (abnormal ipsilateral motor arm and leg, and abnormal language), 'neglect-hemiparesis' (abnormal ipsilateral motor arm and leg, and neglect), 'hemianopsia and hemiparesis' (abnormal ipsilateral motor arm and leg, and abnormal vision), 'lethargic hemiparesis' (abnormal ipsilateral motor arm and leg, and abnormal level of consciousness) and 'brachial pattern of weakness' (motor arm score greater than ipsilateral motor leg score). In addition, we considered the total NIHSS score as a covariate. We did not include the syndrome ataxia-hemiparesis because the NIHSS scoring of ataxia does not specify the side affected. Univariate comparisons were performed using the $\chi^{2}$ test for discrete variables and ANOVA for continuous variables.

We performed 2 polytomous logistic regression analyses using the nominal variable stroke subtype. Unlike logistic regression, which applies dichotomous outcome variables, polytomous logistic regression can analyze outcomes with $>2$ levels. One of these polytomous analyses was conducted on all patients in TOAST, and the nominal outcome variable 'subtype' had 5 different levels (atherothrombotic, cardioembolic, lacunar, 'other' and 'undetermined'). The other polytomous logistic regression analysis was conducted only among the patients with a defined TOAST subtype (the outcome variable 'subtype' had only 3 possible levels: atherothrombotic, cardioembolic and lacunar). The 20 NIHSS covariates, total NIHSS score and atrial fibrillation were used as covariates in both analyses. We established the significance level at $5 \%$, and used the significant variables and atrial fibrillation to construct 3 more parsimonious logistic regression models of subtype prediction. These models were used to generate a table with the probability of finding each of the stroke subtypes in patients 
with no atrial fibrillation based on the responses to those significant NIHSS variables. The model's predicted probabilities were then compared with the actual percentage of patients in the TOAST database for each of the possible combinations of NIHSS predictors. All statistical analyses were performed using SAS version 9.1 (SAS Institute Inc., Cary, N.C., USA).

\section{Results}

The 2 polytomous logistic regression analyses show similar results, independently of whether they were applied to the whole TOAST population or a reduced sample with only 'defined' (lacunar, cardioembolic and atherothrombotic) subtypes (table 1). Based on these results, we choose the significant variables best language, visual field, neglect and brachial predominance of weakness to construct 3 independent parsimonious regression models that were used to create a table of probability for the 3 major stroke subtypes when atrial fibrillation is not present (table 2).

The probability of lacunar stroke dramatically reduces with gradual increases in abnormalities in those NIHSS variables (best language, visual field, neglect and brachial predominance of weakness). Similarly, the probability of cardioembolic and atherothrombotic stroke progressively increases with abnormal responses to those 4 NIHSS variables. For example, a patient with no atrial fibrillation and a normal response to those 4 NIHSS predictors has a $46 \%$ probability of lacunar stroke, $12 \%$ of atherothrombotic stroke and $10 \%$ of cardioembolism. Those predicted figures nicely correlate with the actually observed percentages in the database $(45,13$ and 9\%, respectively). Conversely, a patient with abnormal values for those 4 NIHSS items has a $0.1 \%$ probability of lacunar, $50 \%$ of atherothrombotic and $39 \%$ of cardioembolic stroke.

\section{Conclusions}

A useful early clinical instrument to predict stroke subtype should be simple, applicable and reliable. It should be able to be determined without delays or the need of a large number of diagnostic tests. We have shown that the scores for language, neglect, visual field items, and the presence or absence of a brachial predominance of weakness in the baseline NIHSS exam meet such criteria. The acute responses to these 4 items discriminate between subtypes, in particular between lacunar and nonlacunar ones. This finding has obvious practical im-
Table 2. Probability of finding different stroke subtypes based on the presence or absence of aphasia, visual field abnormalities, neglect and brachial predominance of weakness in a model including all TOAST patients without atrial fibrillation (comparison between predicted and actual values in the TOAST database)

\begin{tabular}{|c|c|c|c|c|}
\hline & & & $\begin{array}{l}\text { Predicted by } \\
\text { model, \% }\end{array}$ & Actual values, $\%$ \\
\hline \multicolumn{5}{|c|}{ No aphasia } \\
\hline & $\begin{array}{l}\text { Negl. } \\
\text { no }\end{array}$ & $\begin{array}{l}\text { BP } \\
\text { no }(\mathrm{n}=529)\end{array}$ & $\begin{array}{l}\text { A (12), C (10), } \\
\text { L (46) }\end{array}$ & $\begin{array}{l}\text { A (13), C (9), } \\
\text { L (45) }\end{array}$ \\
\hline & & $\begin{array}{l}\text { BP } \\
\text { yes }(n=118)\end{array}$ & $\begin{array}{l}\text { A (19), C (14), } \\
\text { L (33) }\end{array}$ & $\begin{array}{l}\text { A (19), C (14), } \\
\text { L (33) }\end{array}$ \\
\hline & $\begin{array}{l}\text { Negl. } \\
\text { yes }\end{array}$ & $\begin{array}{l}\text { BP } \\
\text { no }(\mathrm{n}=48)\end{array}$ & $\begin{array}{l}\text { A (20), C (14), } \\
\text { L (11) }\end{array}$ & $\begin{array}{l}\text { A (15), C (19), } \\
\text { L (13) }\end{array}$ \\
\hline & & $\begin{array}{l}\text { BP } \\
\text { yes }(n=35)\end{array}$ & $\begin{array}{l}\text { A (29), C (19), } \\
\text { L (7) }\end{array}$ & $\begin{array}{l}\text { A (20), C (29), } \\
\text { L (6) }\end{array}$ \\
\hline \multirow[t]{4}{*}{$\begin{array}{l}\text { VF } \\
\text { yes }\end{array}$} & $\begin{array}{l}\text { Negl. } \\
\text { no }\end{array}$ & $\begin{array}{l}\text { BP } \\
\text { no }(\mathrm{n}=43)\end{array}$ & $\begin{array}{l}\text { A (12), C (12), } \\
\text { L (19) }\end{array}$ & $\begin{array}{l}\text { A (23), C (16), } \\
\text { L (21) }\end{array}$ \\
\hline & & $\begin{array}{l}\text { BP } \\
\text { yes }(n=7)\end{array}$ & $\begin{array}{l}\text { A (19), C (17), } \\
\text { L (12) }\end{array}$ & $\begin{array}{l}\text { A (14), C (14), } \\
\text { L (0) }\end{array}$ \\
\hline & $\begin{array}{l}\text { Negl. } \\
\text { yes }\end{array}$ & $\begin{array}{l}\text { BP } \\
\text { no }(n=73)\end{array}$ & $\begin{array}{l}\text { A (19), C (17), } \\
\text { L (3) }\end{array}$ & $\begin{array}{l}\text { A (22), C (19), } \\
\text { L (1) }\end{array}$ \\
\hline & & $\begin{array}{l}\text { BP } \\
\text { yes }(n=35)\end{array}$ & $\begin{array}{l}\text { A (29), C (23), } \\
\text { L (2) }\end{array}$ & $\begin{array}{l}\text { A (34), C (20), } \\
\text { L (0) }\end{array}$ \\
\hline \multicolumn{5}{|c|}{ Aphasia } \\
\hline & $\begin{array}{l}\text { Negl. } \\
\text { no }\end{array}$ & $\begin{array}{l}\text { BP } \\
\text { no }(\mathrm{n}=140)\end{array}$ & $\begin{array}{l}\text { A (26), C (19), } \\
\text { L (4) }\end{array}$ & $\begin{array}{l}\text { A (31), C (19), } \\
\text { L (4) }\end{array}$ \\
\hline & & $\begin{array}{l}\text { BP } \\
\text { yes }(n=8)\end{array}$ & $\begin{array}{l}\text { A (37), C (25), } \\
\text { L (2) }\end{array}$ & $\begin{array}{l}\text { A (0), C (12), } \\
\text { L (12) }\end{array}$ \\
\hline & $\begin{array}{l}\text { Negl. } \\
\text { yes }\end{array}$ & $\begin{array}{l}\mathrm{BP} \\
\text { no }(\mathrm{n}=39)\end{array}$ & $\begin{array}{l}\text { A (37), C (26), } \\
\text { L (0.6) }\end{array}$ & $\begin{array}{l}\text { A (38), C (23), } \\
\text { L (3) }\end{array}$ \\
\hline & & $\begin{array}{l}\text { BP } \\
\text { yes }(n=5)\end{array}$ & $\begin{array}{l}\mathrm{A}(50), \mathrm{C}(34) \\
\mathrm{L}(0.3)\end{array}$ & $\begin{array}{l}\mathrm{A}(60), \mathrm{C}(0) \\
\mathrm{L}(0)\end{array}$ \\
\hline \multirow[t]{4}{*}{$\begin{array}{l}\text { VF } \\
\text { yes }\end{array}$} & $\begin{array}{l}\text { Negl. } \\
\text { no }\end{array}$ & $\begin{array}{l}\text { BP } \\
\text { no }(\mathrm{n}=70)\end{array}$ & $\begin{array}{l}\text { A (25), C (23), } \\
\text { L (1) }\end{array}$ & $\begin{array}{l}\text { A (26), C (29), } \\
\text { L (1) }\end{array}$ \\
\hline & & $\begin{array}{l}\text { BP } \\
\text { yes }(n=3)\end{array}$ & $\begin{array}{l}\text { A (36), C (30), } \\
\mathrm{L}(0.6)\end{array}$ & $\begin{array}{l}\text { A }(0), C(0), \\
L(0)\end{array}$ \\
\hline & $\begin{array}{l}\text { Negl. } \\
\text { yes }\end{array}$ & $\begin{array}{l}\text { BP } \\
\text { no }(\mathrm{n}=74)\end{array}$ & $\begin{array}{l}\text { A (39), C (31), } \\
\text { L (0.2) }\end{array}$ & $\begin{array}{l}\text { A (36), C (20), } \\
\text { L (1) }\end{array}$ \\
\hline & & $\begin{array}{l}\text { BP } \\
\text { yes }(n=6)\end{array}$ & $\begin{array}{l}\text { A (50), C (39), } \\
\text { L (0.1) }\end{array}$ & $\begin{array}{l}\text { A (17), C (33), } \\
\text { L (0) }\end{array}$ \\
\hline
\end{tabular}

The subtype values do not add to $100 \%$ because those with undefined subtype are not shown. VF = Visual field deficit; Negl. $=$ neglect; $\mathrm{BP}=$ brachial predominance; $\mathrm{L}=$ lacunar; $\mathrm{A}=$ atherothrombotic; $\mathrm{C}=$ cardioembolic.

plications for stroke research and practice. Clinical trials are criticized for potentially diluting the benefit of the intervention by enrolling stroke patients who are unlikely to benefit from it [12]. Since standard subtype diagnosis with ancillary tests imposes an unacceptable delay for 
an acute stroke intervention, the most feasible strategy for clinical trials is to stratify patients by likely subtype based on the already available NIHSS clinical data. Additionally, these 4 NIHSS items could help stratify patients for subsequent ancillary studies for cardioembolism or atherothrombotic stroke depending on the likelihood of finding such subtypes when resources are limited. These findings add to the practical applications of the NIHSS, an instrument already used worldwide in the initial evaluation of stroke because of its reproducible results across a variety of health professionals [13] and that has the ability to predict the functional outcome at 3 months [14].

We recognize that a limitation of this study is the fact that the predictor variables are partially incorporated in the definition of the outcome variable, which could understandably raise concerns of a self-fulfilling prophecy. It should be stressed, however, that the importance of these data is not that such association exits but the fact that for the first time we have quantified its degree independently of the other variables. In addition, while the NIHSS exams were performed by local investigators, the outcome variable (subtype determination) was done by a central investigator (H.P.A.) blinded to the NIHSS data and with no direct contact to the patient. We realize that another limitation is the use of the original standard TOAST subtype classification. Modifications to the subtype classification are expected with progress in ancillary diagnostic tests [15], which might affect the observed relationship between baseline NIHSS variables and subtype.

There have been previous attempts to stratify acute stroke patients by likely subtype based on clinical presentation. Patients with classical lacunar syndromes [16] or very low NIHSS scores $[17,18]$ have been excluded from clinical trials primarily targeted at non-lacunar strokes. Toni et al. $[6,19]$ previously questioned the predictive value of 2 specific stroke syndromes, pure motor hemiparesis and sensorimotor stroke, for screening lacunar strokes. However, a recent secondary analysis from the Glycine Antagonist in Neuroprotection Americas trial has revived the value of an emergent impression of lacunar syndrome to screen for small vessel disease. Using the $\mathrm{Ox}$ fordshire Community Stroke Project criteria [20], the investigator's initial impression of a 'lacunar syndrome' coincided $76 \%$ of the time with a lacunar stroke subtype determination at 7 days using the TOAST classification [21]. This finding is not surprising, since having a 'lacunar syndrome' is part of the TOAST criteria for making a determination of a small vessel stroke. However, since the initial impression using the Oxfordshire Community
Stroke Project and the 7-day TOAST subtype were done by the same local investigator, an initial clinical impression of lacunar syndrome could have potentially influenced a subsequent lacunar TOAST classification. Another limitation is that such an initial impression of lacunar syndrome occurred in only $14 \%$ of the population studied. In fact, for the majority of patients with a nonlacunar initial impression according to the Oxfordshire Community Stroke Project, no reliable inference about the TOAST subtype could be done.

In this study we have analyzed individual NIHSS items and combinations of these items using a novel clinimetric approach to standardize clinical syndromes using patterns of responses in the NIHSS. We believe this approach is better than using a phenomenological scale based on a general impression. For example, an impression of 'lacunar syndrome' is complex and could be influenced by variables other than the neurological exam, such as the history and 'ecology' of the patient. By using a logistic regression approach we were able to determine the true strength of the association between NIHSS item stroke subtypes independently of other covariates on the scale and potential confounding factors (such as atrial fibrillation). Other strengths of our study include the use of a large cohort of patients carefully evaluated in a standardized manner. By adjusting our analysis to the patients with known atrial fibrillation at the time of the NIHSS evaluation, our research becomes relevant to clinical practice by replicating a common situation in the decision-making with acute stroke patients.

We conclude that the language, neglect and visual field items of the baseline NIHSS and the presence of a brachial predominance of weakness are helpful to predict the probability of finding lacunar and nonlacunar stroke, and could be used for emergent stratification of patients for subtype-specific acute therapies.

\section{Acknowledgement}

Funded in part by NIH 5K12RR017700-04 (Mentored Clinical Research Scholar Program at Iowa) to E.C.L., MD, MS (PI Allyn Mark, MD). 


\section{References}

1 Timsit SG, Sacco RL, Mohr JP, et al: Early clinical differentiation of cerebral infarction from severe atherosclerotic stenosis and cardioembolism. Stroke 1992;23:486-491.

$\checkmark 2$ Adams HP Jr, Bendixen BH, Leira E, et al: Antithrombotic treatment of ischemic stroke among patients with occlusion or severe stenosis of the internal carotid artery: a report of the Trial of Org 10172 in Acute Stroke Treatment (TOAST). Neurology 1999;53: 122-125.

$\checkmark 3$ Madden KP, Karanjia PN, Adams HP Jr, Clarke WR: Accuracy of initial stroke subtype diagnosis in the TOAST study. Trial of ORG 10172 in Acute Stroke Treatment. Neurology 1995;45:1975-1979.

$\checkmark 4$ Adams HP Jr, Bendixen BH, Kappelle LJ, et al: Classification of subtype of acute ischemic stroke: definitions for use in a multicenter clinical trial. TOAST. Trial of Org 10172 in Acute Stroke Treatment. Stroke 1993;24:35-41.

5 Hand PJ, Wardlaw JM, Rowat AM, Haisma JA, Lindley RI, Dennis MS: Magnetic resonance brain imaging in patients with acute stroke: feasibility and patient-related difficulties. J Neurol Neurosurg Psychiatry 2005; 76:1525-1527.

-6 Toni D, Iweins F, von Kummer R, et al: Identification of lacunar infarcts before thrombolysis in the ECASS I study. Neurology 2000;54:684-688.
7 Kasner SE, Kimmel SE: Accuracy of initial stroke subtype diagnosis: a decision analysis. Cerebrovasc Dis 2000;10:18-24.

$\checkmark 8$ Brott T, Adams HP Jr, Olinger CP, et al: Measurements of acute cerebral infarction: a clinical examination scale. Stroke 1989;20: 864-870.

$\checkmark 9$ Rovira A, Grive E, Rovira A, Varez-Sabin J: Distribution territories and causative mechanisms of ischemic stroke. Eur Radiol 2005; 15:416-426.

10 Arboix A, Oliveres M, Massons J, Pujades R, Garcia-Eroles L: Early differentiation of cardioembolic from atherothrombotic cerebral infarction: a multivariate analysis. Eur J Neurol 1999;6:677-683.

11 Publications Committee for the Trial of ORG 10172 in Acute Stroke Treatment (TOAST) Investigators: Low molecular weight heparinoid, ORG 10172 (danaparoid), and outcome after acute ischemic stroke: a randomized controlled trial. JAMA 1998;279:12651272 .

12 Sterman AB, Furlan AJ, Pessin M, Kase C, Caplan L, Williams G: Acute stroke therapy trials: an introduction to recurring design issues. Stroke 1987;18:524-527.

13 Goldstein LB, Samsa GP: Reliability of the National Institutes of Health Stroke Scale: extension to non-neurologists in the context of a clinical trial. Stroke 1997;28:307-310.

14 Adams HP Jr, Davis PH, Leira EC, et al: Baseline NIH Stroke Scale score strongly predicts outcome after stroke: a report of the Trial of Org 10172 in Acute Stroke Treatment (TOAST). Neurology 1999;53:126-131.
15 Ay H, Furie KL, Singhal A, Smith WS, Sorensen AG, Koroshetz WJ: An evidencebased causative classification system for acute ischemic stroke. Ann Neurol 2005;58: 688-697.

16 Higashida RT, Furlan AJ, Roberts H, et al: Trial design and reporting standards for intra-arterial cerebral thrombolysis for acute ischemic stroke. Stroke 2003;34:e109-e137.

17 Abciximab Emergent Stroke Treatment Trial (AbESTT) Investigators: Emergency administration of abciximab for treatment of patients with acute ischemic stroke: results of a randomized phase 2 trial. Stroke 2005;36: 880-890.

18 Lees KR, Zivin JA, Ashwood T, et al: NXY059 for acute ischemic stroke. N Engl J Med 2006;354:588-600.

19 Toni D, Del Duca R, Fiorelli M, et al: Pure motor hemiparesis and sensorimotor stroke: accuracy of very early clinical diagnosis of lacunar strokes. Stroke 1994;25:92-96.

-20 Bamford J, Sandercock P, Dennis M, Burn J, Warlow C: Classification and natural history of clinically identifiable subtypes of cerebral infarction. Lancet 1991;337:1521-1526.

21 Phillips SJ, Dai D, Mitnitski A, et al: Clinical diagnosis of lacunar stroke in the first 6 hours after symptom onset: analysis of data from the glycine antagonist in neuroprotection (GAIN) Americas trial. Stroke 2007;38: 2706-2711. 